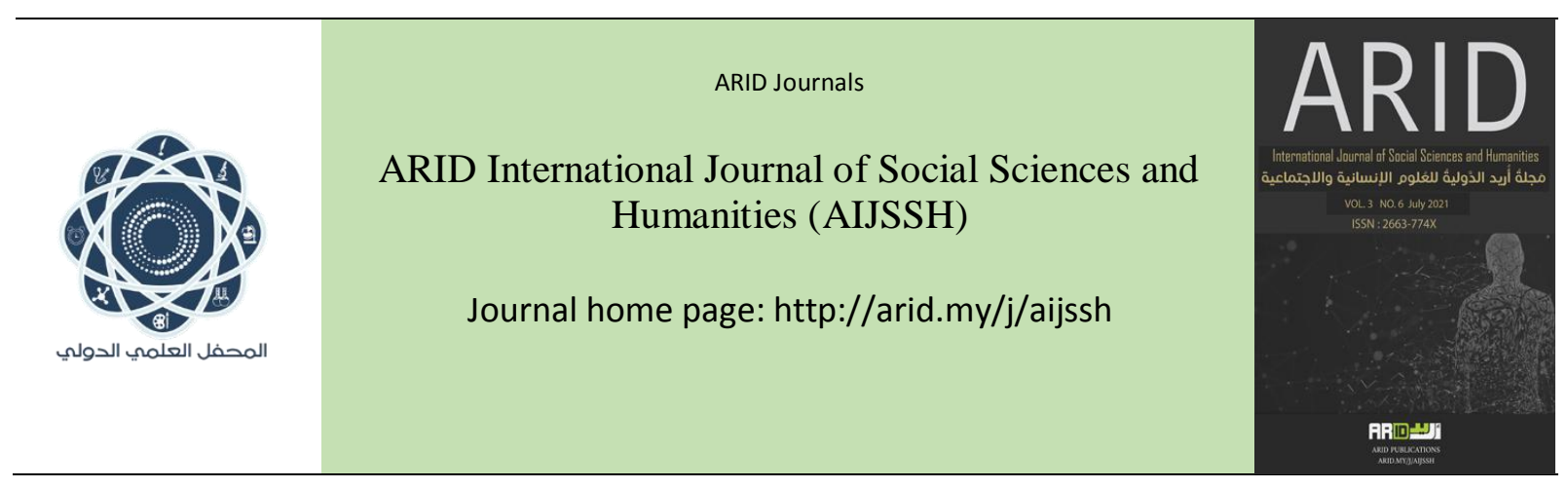

$$
\begin{aligned}
& \text { مَجلةُ أُريد الدَّوليُُّ للعُلومِ الإنسانية والإجتماعية } \\
& \text { البجلد الثالث ،العدد السادس، تموز } 2021 \text { م }
\end{aligned}
$$

\title{
The Textual Structure of Al-Fajur Sura (A Reading in Congruity and Consistency)
}

\author{
wsaan Abd Ali Attya. \\ Noha Hussein Kandoh
}

University of Al-Qadisiyah-College of Education-Department of Arabic Language

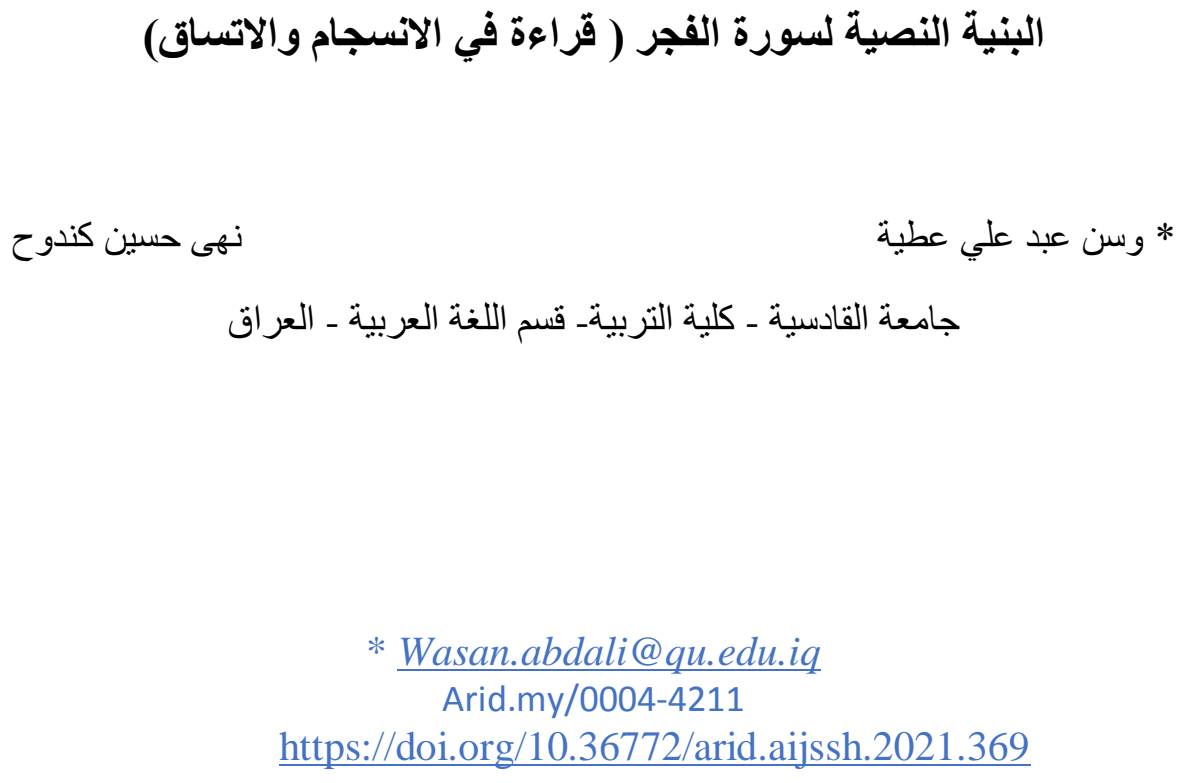




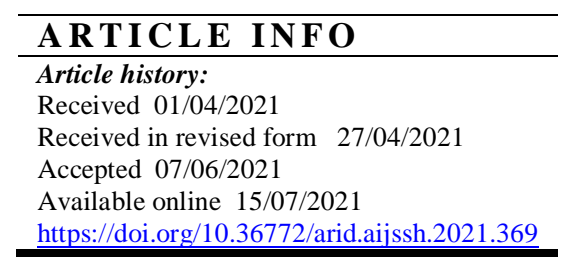

\begin{abstract}
Each text has its own structure, which is different from other texts. This structure is the identity acquired from the author, who gives the text part of his experience and culture that shows high congruity and consistency of the structure. Each structure needs its own system of organizing ideas and information in a way that affects the receiver.

The aim of the text's author is to influence the receiver and create a channel of communication between the text and the receiver to determine the author's intention. Therefore, the study revealed a unique and unparalleled structure, that is the structure of the Qur'anic text, which is considered the highest level of congurity and textual consistency. The researcher has selected Surat Al-Fajur to reveal the aesthetics of this unique textual structure. The study is divided into four levels of structures, phonological, morphological, structural , and semantic one.
\end{abstract}




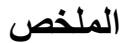

لكل نص بنية ينماز بها عن بقية النصوص التي تعد هويته التي يكتسبها من خلال منشئه الذي بضفي عليه من خبراته وتثافته شيئاً

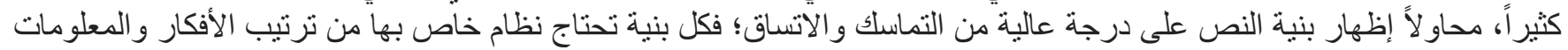
بشكل يؤثر على المنلقي.

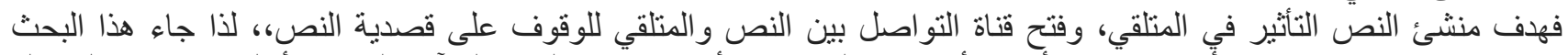

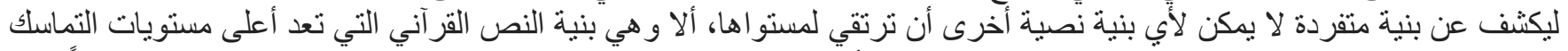

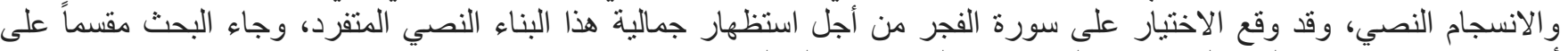
أربعة مستويات بنيوية، البنية الصوتية، والصات الصرفية الصية، والتركية التيبية، و الدلالية.

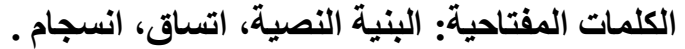


الحمد لله بجميع محامده كُلَّها على جميع نعمه كلها، و الحمد لله الذي أخرجنا من ظلمات الجهل إلى نور الإسلام، وأصلي وأسلم على خير الورى المصطفى و على أل بيته الطيبين الطاهرين.

إن سور القرآن الكريم وحداتُ منر ابطة متكاملة مُحكمة، وكذا آياته الثريفة فوجودها - باختلاف مر اميهاـ داخل هذه الوحدة الرصينة ليس عبثاً، أو صدفة، ودر اسة أي من سور القرآن يتطلب الوقوف على مقاصدها التي فرضت هذه البنية النصية.

\section{هدف البحث وأهميته:}

ما يخص بحثنا هو سورة الفجر ، ليس جديداً في مجاله؛ فقد سبقتنا در اسات كثيرة تناولت الاتساق و الانسجام بالنص القر آني وغيره، لكن طبيعة النص القر آني تختلف عن بقية النصوص فبنيته المتفردة وإعجازه المُتعاضم يجعله مجالاً خصباً ورحباً للار اسين، وكلما زاد التنقيب انكثفت جماليات النص القر آني ومن هنا تظهر أهمية البحث، وهذه السورة من السور المكية التي لا خلاف فيها، وهي خمسمائة وسبعة وتسعون حرفاً، ومائة وتسع وثلاثون كلمة، و عدد آياتها ثلاثون آية، وتسلسل نزولها على النبي (صل اله عليه و آله وسلم) الثالثة عشرة سبقتها سورة الليل، و أعقبتها سورة الضحى [1]، و هذا التسلسل يُحسب من لطائف التنزيل تارة، ولتناسق اسمها مع أزمنة الليل و النهار التي جاءت بها أسماء السور تتابعاً نارة أخرى، ولهذا النسق الخارجي الرائع ترابط نصي وبنية متناسقة في غاية الدقة والحبكة. منهج البحث: اعتمد البحث على المنهج الوصفي التحليلي في استقصاء المادة البحثية و عرضها .

\section{1 البنية الصوتية}

بكُرَتْْ الدر اسات اللغوية بعلم الأصوات في أي مجال لغوي يُر اد الخوض و البحث فيه، فاللغة قبل أن تكون كلاماً أو حروفاً ولها معنى معين فهي أصو ات، ولتلك الأصو ات ظو اهر وصفات من خلال تشكيلها نتمكن من بناء الأساس الأول لتلك الدراسات.

ومن الممكن القول أن اللغة التي يتكلّمها الفرد تمثل إحدى المميزات الهامة له، فطبيعة الصوت نفسها تحدد نوع ذلك الفرد فيما إذا كان طفلاً أو بالغاً، أو أنتى أو ذكر، كما أن طبيعة الصوت يمكن أن تجدد طبعه ومز اجه [2]، في ضوء هذا التحديد لا يمكننا القول بأن من خلال لغة القرآن الكريم وظو اهر ها يمكننا أن نعرف مميزات وطبيعة القائل - حاثا لله عز وجلـ فالقرآن نزل بلغة قوم لا لغة قائل. ولنعاود القول بأن علم الأصوات في در اسة سورة قرآنية يؤسس للَّنات التي توصل إلى ما بعده من جانب صرفي ونحوي ودلالي، وستتاول في البنية الصوتية الفاصلة، والنبر، و التنغيم لأنها من الظواهر الصوتية الأكثر شيوعاً في السور القر آنية، فمن الغرض البلاغي الوقوف عند الفواصل لتقع في الأسماع فتتأثر نفوس السامعين بمحاسن ذلك التماثل كما تتأثر بالقو افي في الثعر، وبالأسجاع في الكلام 
المسجوع [3]و الفاصلة " تنضوي على دلالتين هامتين الأولى: دلالة صوتية تتمنل في الإيقاع والرنين الصوتي المحكوم بنسق الآية و السياق العام، و الدلالة الثانية: دلالة معنوية تحمل تمام الفكرة في الآية"[4] وقد تتوعت الفواصل في هذه السورة المباركة، وسنتناول الفاصلة بحسب الوزن وتقسيماتها.

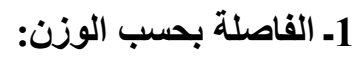

أ ـ الفاصلة المتوازية: هي رعاية الكلمتين الأخيرتين في الوزن وحرف الروي، وهذا ما جاءت به السورة في آياتها الأولى التي كانت

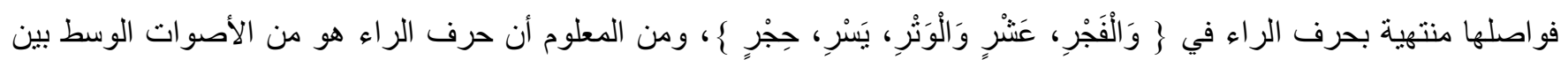
الثديدة والرخوة [5] فتتاسقت الفاصلة المنتهية بهذا الحرف وبوزن ووتيرة واحدة مع جو الآيات الخمس الأولى التي تناسبت مع الهذوء و السكينة وفرصة التأمل في وقت الفجر، وكذلك مع قدسية الليال العشر، وما في الليل من صلاة ( الثفع و الوتر )، وسريان الليل بهدوء، كل ذلك مهد الطريق و هيأ الآذان وجعلها مذعنة لما سيأتي من وصف وبلاغ فيما بعدها، وهي أكثر فواصل السورة على القارئ و السامع

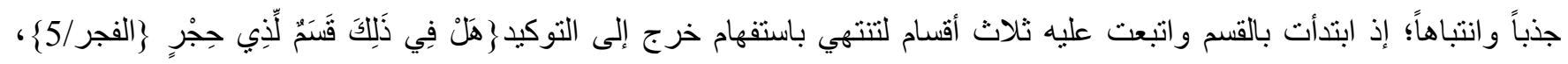
و معنى (هل) " ها هنا للتأكيد، كما قال أبن عباس: يريد إن في ذلك قسماً لذي لبّ و عقل، والمعنى: إن من كان ذا لبّ عَلِمَ أن ما أقسم الله به من هذه الأشياء فيه عجائب ودلائل على صنع الله وقدرته وتوحيده، فهو حقيق بأن يُقسم به لدلالته على خلقه ومدبّره بالحكمة"[5]، أما الآيات (19، 20، 22،21) المنتهية فو اصلها بالألف المنون: ( لمّاً، جماً، دكّاً، صفّاً)، فجاءت أيضاً بوزن وحرف روي واحد، إلاّ أن الوقف هنا يكون على حرف الألف " فالتنوين إن كان بعد فتحة في غير مؤنث بالهاء أُبْدل ألفاً نحو : رأيتُ زيدا"[6] ب ـ الفاصلة المطرّفة: وهي ما اتفقت كلمتان بحرف الروي دون الوزن، وقد تمثلت في كل من الآيات التسع بعد الخمس الأولى: (

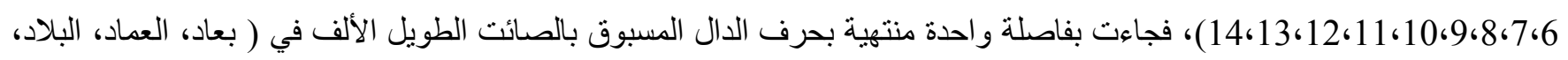

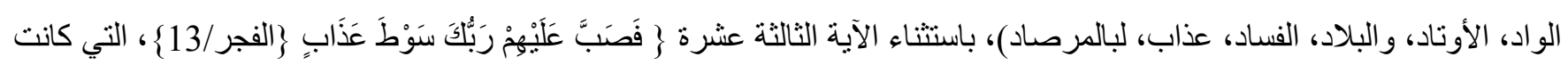
فاصلتها منتهية بحرف الباء وهذه الفاصلة المنتهية بحرف الدال فيها جانبان هما: أـ الجانب الأول: إنّها انتهت بحرف الدال الذي يحمل صفة الثنَّةّة في النطق، إذ ينحبس الهواء في مخرج حرف الدال لينتهي بصوت انفجاري حال سريانه [7]، أضف إلى ذلك أنه في حال الوقوف عليه بسبب الفاصلة يكن ساكناً فيلزم صفة القلقة التي هي عبارة عن طول في الصوت عند النطق بالحرف؛ لئلّا يُههس الحرف المجهور الثُديد.

ب ـ الجاتب الثاني: إن هذه الفاصلة قد سبق حرف الدال صائت طويل (الألف)، و هنا تشكل عندنا حرف مذّ لتحقّق سببين هما، مجيء حركة من جنس الصائت الطويل مع وجود أحد أسباب المدّ وهو سكون الحرف الذي يلي الصائت حال الوقف، وهذا ما أشار إليه ابن 
جني في خصائصسه في باب أسماه " مطل الحروف"[8]، ولحرف المد ها هنا أثر نفسي على المستمع أكثر منه على القارئ، فمن خلال ذلك المطل في صوت الألف ذبي المساحة الواسعة الامتداد، يهيّئ وقتاً لا بأس به لوقفة تأمل وتفكر قبل أن تنتهي الفاصلة وقبل إتمام المعنى في نهاية الآية، ومن خلال هذين الجنبين المتمثلين بحرف القلقة الانفجاري وحرف المدّ الذي سبقه، بتضح لنا الملائمة بين تمام المعنى لكل فاصلة على حدة، وبين وحدة الموضوع الذي جاءت به الآيات بفاصلة واحدة، فهذه الآيات كانت " اعتراض بين القسم وجو ابه، و هي خطاب للنبي (صلى الله عليه و آله وسلم) وتتبيه للكفار على ما فعله سبحانه بالأمم السالفة، لما كفرت بالهه وأنبيائه، وكانت

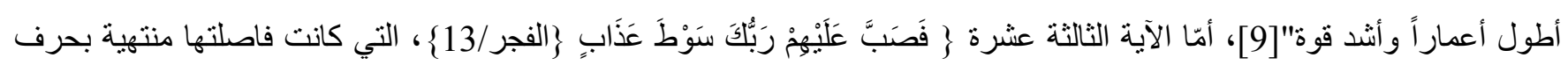
الباء إذ أتت مختلفة بحرف الروي عن أخواتها، نعم، لقد هنا قُطع السياق الصوتي وجيء بحرف يشترك بحرف الدال في صفاته، كونها من حروف الثَّدة والقلقة، ما جعل المتلقي لا يحسّ بالخروج من الفاصلة سوى صوت مختلف المخرج، ولعل هذا الخروج فيه شيء من إلفات النظر إلى جزاء الأقوام التي ذُكرت.

بقي عندنا بعض آيات تتنمي إلى الفاصلة المطرّةفة وهي ( 30,29,24) بحرف روي واحد وهو الياء: (لحياتي، عبادي، جنّي)، فالآية

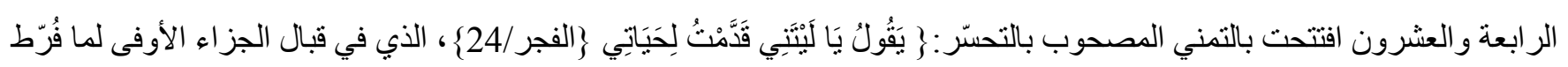

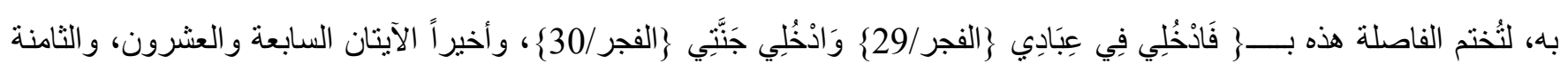

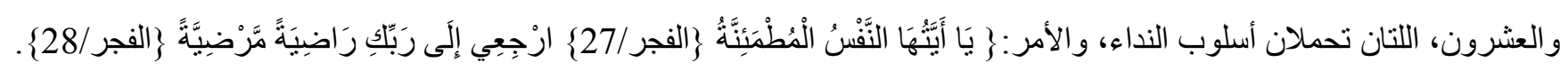

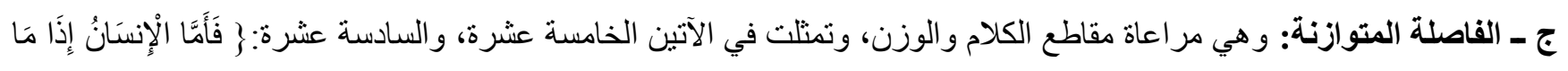

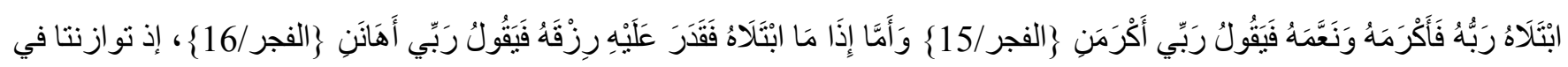
مقاطع الكلام والوزن، ومن المفترض أن تنتهي الفاصلة بحرف الياء وهو الضمير المتصل بالفعلين الماضيين: ( أكرمن، وأهاننِ)، " فحذفوا الياء اختصار اً، وأبو عمر ونافع يُتنتانِها وصلاً ويحذفانها وقفاً "[10]، ومعنى هذا أنَّ الياء مثبتة وصلاً، ومحذوفة لمراعاة الفاصلة . وأخيراً يمكننا القول من باب التقريب ليس إلّا هو إن سورة الفجر وبعض السور المكية، في أوائلها شيء من الجذب والإذعان للآذان العربية، إذ إنَّ العرب أمّة شاعرة تميل للإيقاع و النظم المزون، و عندما كانت كذلك جاء القرآن بأسلوب وخطاب محبّب لديهم وقريب من استعمالاتهم .

2- النبر: هو نشاط عضوي تنشط فيه جميع أعضاء النطق غاية النشاط عند النطق به [11] وفي النبر وضوح نسبيّ لصوت أو مقطع إذا قورن بيقية الأصوات والمقاطع في الكلام [12]، يُحكم على مواضع النبر في الكلام من خلال نوع المقطع الصوتي، وهذا يمكن 
مراجعته في المصادر التي تتحدث عن المقاطع الصوتية، ومن المواضع التي وقع النبر فيها بسورة الفجر منها في كلمات ومنها في جمل:

أــ النبر في الكلمة: وقع النبر في كل كلمة أقسم الله بها: ( الفجر، وليال عشر، والوتر ، يَسر ) تلك الكلمات انتهت بالمقطع (ص ح ص ص)، ومن الو اضح إن الإنسان إذا ما أراد أن يُقسمَ بشيءٌ عزيز له، أو بيان أمر مهمّ، أو من أجل أن يصدّقه الآخرون، يجعل التركيز في النطق عليه دون غيره من الكلام، فكيف بالبارئ المصوّر إذ أقسم بمخلوقات عظيمة الصنع، جليلة القدر ليفتح مغالق العقول نحو بصيرة التفكّر بما خلق، ولعل قائلاً يقول أي عظمة وأي قدر في تلك الأقسام؟ لقد اختلف المفسرون بحسب تعدّد الروايات في بيان تلك الأقسام، أمّا الفجر فقد فسّره بعضهم بأنّه صلاة الفجر ، أو هو شقّ عمود الصبح، أو فجر يوم عرفة، أو فجر محرّم الذي تتفجّر منه السنة، أو انفجار الصبح من كل يوم إلى انقضاء الدنيا [13] ولكل قدْر " ومَحَط" تفكّرٍ.

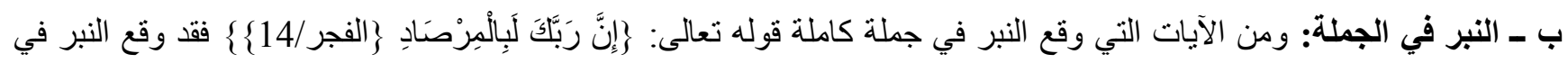

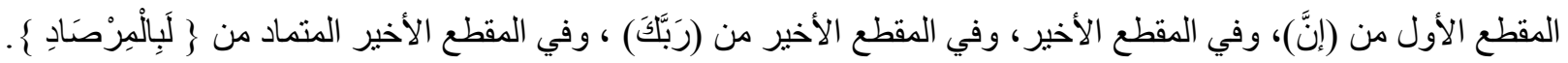

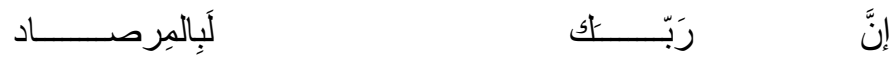

$$
\begin{aligned}
& \text { ص ح+ص حص+ص حص+ص ححص } \\
& \text { صح ص+صح صحص ص+ص+صح }
\end{aligned}
$$

فجاء هنا توكيد على أن الله برصد الأعمال ولا يفوته شيء[14]، وروي عن علي ـعليه السلام- أنه قال: " مهناه أن ربك قادر على أن يجزي أهل المعاصي جزاءهم، وعن الصادق - عليه السلام- أنه قال: المرصاد قنطرة على الصراط لا يجوز ها عبد بمظلة عبد"[15]، فكان النبر و البروز من لوازم الكلام الذي يقتضيه المعنى. 3- التنغيم: هو ما دلَّ عل ارتفاع وانخفاض في درجة الجهر في الكلام [16]، ولقد أَلِفَ العربي الإيقاع في حديثه وشعره ونثره، فقد حَفِت الخطب ذات السجع و القصائد ذات الوزن و القافية بالموسيقى والنغم، وللغة العربية مواطن غنيّة تُري النص رونقاً وجمالاً من خلال تعدّد الكلمة أو الجملة بمعانٍ عدة يكثفها نبر الكلمة ونغمها، وربّما كان للتنغيم وظيفة نحوية هي تحديد الإثبات والنفي في جملة لم تستعمل فيها أداة استفهام، أو لها وظيفة دلالية [17]، و هنالك معياران أجمع عليها الدحدثون: [18]. 1- يُعتمد على نغمة الحرف الأخير وهي إمّا هابطة تصدر من أعلى إلى أسفل في الإثبات و الاستفهام والنفي و الثرطرو الدعاء، وإمّا صاعدة وتتجه من أسفل إلى أعلى وتظهر في الاستفهام بالهمزة وهل. 
إذا ما أردنا تمثيلاً لهذا النوع في سورة الفجر، فستظهر النغمة الهابطة هي أكثر حضوراً في السورة، بخلاف النغمة الصاعدة التي

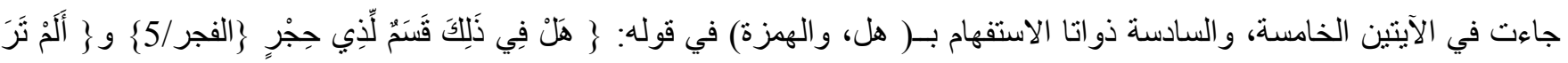
كَيْفَ فَعَلَ رَبْكَكَ بِعَادٍ \}الفجر/6 ، و وجه الاستفهام في الآية الأولى المر اد من التأكيد، أو للتقرير وتفخيم أمر المقسم به والتأكيد والتقرير كلاهما مما تكتفي به الصنعة البلاغية [19]، أمّا الهمزة في \} أَلْمْنَرَ جُ ،هنا جاء التوبيخ في لفظ الاستفهام [20].

2- يُعتمد على المدى بين أعلى نغمة وأخفضها في الصوت، وهي إما واسعة وتكون باندفاع قوي في عمود الهواء المتجه من الرئتين إلى الخارج عبر أعضاء النطق فيحدث صوتاً عالياً وتستخدم في الخطابة، أو التدريس، أو متوسطة باندفاع أقل في الهواء وتستعمل في الكلام العادي و العبار ات الحزينة، وممّا جاء في سورة الفجر على وفق التوسط باندفاع الهو اء في الآية الر ابعة و العشرين \} يَقُّلُ يَا لَيْنَّي قَدَّمْتُ لِحَيَاتِي \}الفجر/24\{ التي تتضمن معنى التحسر والحُزن على ما فات وفرّط في الدنيا من زادِ لتلك الحياة الحقيقية.

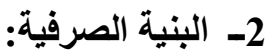

للمستوى الصرفي أهمية لا تقل عن المستويات اللغوية الأخرى في تحليل النص اللغوي، وتأتي هذه الأهمية من خلال دلالة الكلمة ومعناها الذين تكثفهما البنية الصرفية، فلكل صيغة صرفية معنيً يكمن في تشكل حروفها من زيادة أو نقصان أو غير ذلك، ونتناول في هذا المستوى بعض الأبنية الصرفية لسورة الفجر ومنها: دلالة صيغة فَعَل، ودلالة صيغة مِفْعال، ودلالة الفعل الثناثي المضعّف.

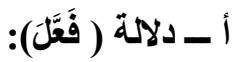

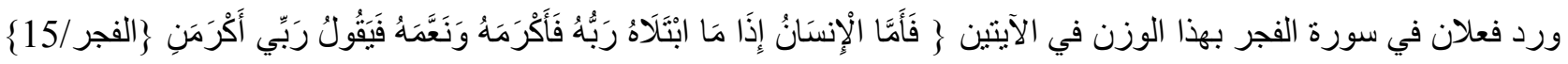

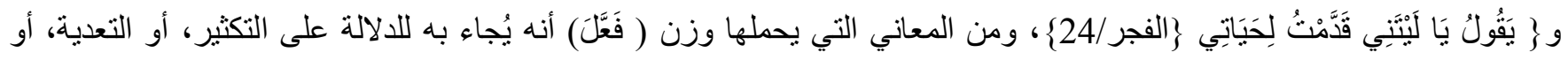
للدلالة على نسبة المفعول إلى أصل الفعل [21] فالفعل \}َنَعَمَهُج يمكن أنه جمع المعنبين؛ الكثرة و التعدية، ويذكر أي ـ الكثرة و التعديةـ "

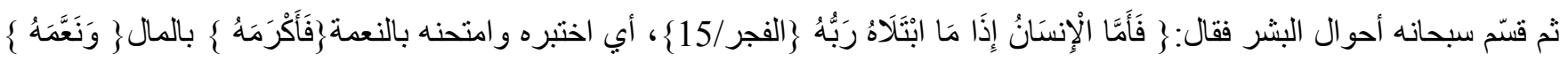
بما وسع عليه من أنو اع الإفضسال \} وَنَعََّهُ \{ فيفرح بذللك ويسر"[22]، أي جعله في لين عيشٍ وخصب[23]، أما الآبة الأخرى فقد جاء الفعل (قَََّمْتُ)، بدل على التكثير و التعدية، فالتكثثر أن التقديم يكون لتلك الحياة الحقبقية التي أشـار الله إليها. 


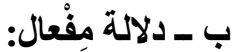

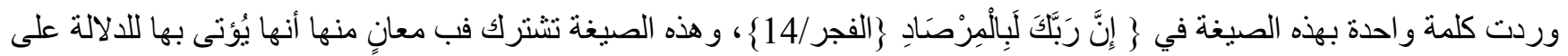
المبالغة، وقد ذكر اللغويون أنَّ صيغة ( مِفعال) لمن اعتاد الفعل أو دام عليه [24]، ومعنى الآية إن الله على طريق العباد فلا يفوته أحد، بمعنى أنه لا يفوته شيء من أعمالهم " [25] وجاءت المادة ست مرّات كلّها في المر اقبة الثديدة التي لا تُقلت شيئًا مما يُرصد بالسمع وبالبصر "26]

\section{3- البنية التركيبية:}

يعد التركيب أحدى وسائل انتاج الدلالة؛ لأنها تتولد منه، ويستمد وجودها وكيفياتها ومداها من ارتباطاته، و عليه فإن التركيب متى أفقد الدلالة أفقد قيمته؛ لأنه إنّما وضع لأجلها وصيغ لتوصيلها [27]، وسنعرض للبنية التركيبية لسورة الفجر من خلال بعض الأمور النحوية منها: الذكر والحذف، و المبني للمجهول.

أــ الذكر والحذف: هما أسلوبان رائجان في علم البلاغة قد استعبر ا من النحو كغير هما، والذَّكر هو أصل في الكلام و الإسهاب في الذكر من تو الي الكلمات أو المعاني يصبّ في غرض أُريد بحسب المقام، أمّا الحذف فهو " أحد الأساليب البلاغية التي ثرمي إلى غاية معينة؛ منها تجنب الإطناب، ومنها إرادة تجنّب التصريح بالعنصر المحذوف، ومنها الاعتماد على دلالة القرائن إذ لا حذف إلا بدليل"[28] 1- هنالك كلمات جاءت محذوف منها حرف الياء، وهي ( يَسْرِ، بالو ادِ، أكرمنِ، أهانِِ)، والحذف - ههنا على الأغلب - لتوافق الفو اصل، قال سيبويه" و أمّا الأفعال فلا يُحذف منها شيء، لأنها لا تذهب في الوصل في حال، وجميع مالا يُحذف في الكلام وما يُختار فيه أن لا يُحذف، يُحذف في الفو اصل والقو افي"[29]، وقرأ كل من نافع وأبي عمر (يسري) بإثبات الياء الوصل، وقرأ ابن كثير بياء في الوصل و الوقف، و الباقون بغي ياء وصلاً ووقفاً، ومن أثبت الياء؛ فلأنها الأصل ومن حذفها، فلأنها رأس آية [30]، ويمكن أن يكون حذف الحرف من الفعل للدلالة على أنَّ الحدث أقل مما لم يحذف منه، أو أنَّ الحذف يكون في مقام يتطلب الإيجاز ، و إذا كان المقام يتطلب التقصيل لم يُقتطع من الفعل[31]،و إذا اردنا مقاربةً للذي ذُكر نمثل بالآيات الآتية لا على سبيل الجزم.

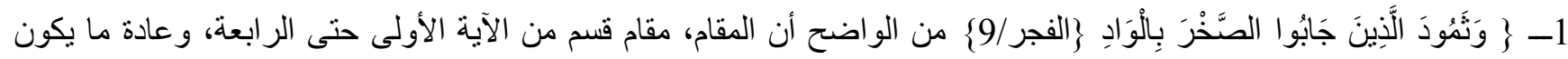
القسم ممهداً وجاذباً للأسماع للإبلاغ وبيان أمور مهمة، فلا داعي للتفصيل في القسم، فكان الحذف مو اكب مع الإيجاز. 


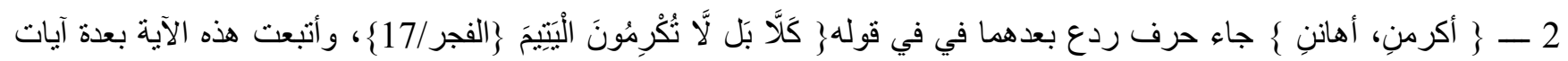
لوصف أولئك الصنفين، فقطع الياء هنا، ربّما يدلّ على دحضاهم، فالردع أي ليس الإكرام بالغنى والإهانة بالفقر وإنّما هو بالطاعة و المعصية وكفار مكة لا ينتبهون لذلك[32].

وفي قبال هذا الحذف - حذف الياء- نجد أن الياء لم تُقطع من كلمة عبادي في قوله: (فادخلي في عبادي\{، فلا وجود لتناسق الفاصلة في الآيات الأخيرة للسورة، أو أن المقام يسع للذكر، فلآية جاءت بعد نداء وخطاب تشريفي ومعنى الآية " أب انضمي إلى عبادي المقربين، و هذه حالة شريفة"[33]، كما إن ذكر الياء فيه شيء من التحقيق للمقام الخاص بأولئك العباد عن غبر هم، ففي سورة الزمر جاءت كلمة

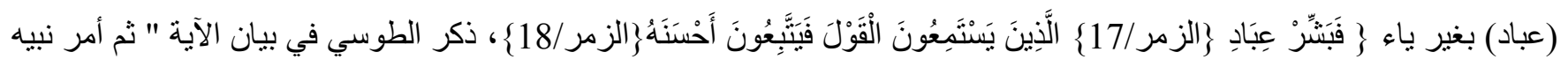
(صلى الله عليه وآله) فقال ( فبشر عبادي)، فمن أثبت الياء وفتحها، فلأنه الأصل، ومن حذف الياء اجنز أ بالكسرة الدالة عليها، ثم وصف عباده الذين أضافهم إلى نفسه على وجه الاختصاص"[34]، والفارق بين (عبادي) في سورة الفجر، و (عباد) في سورة الزمر ،أن في الأولى معنئ أكثر رفعة ومقاماً مما في الثانية، كما أن في الأولى التي جاءت بذكر الياء كان المتحدث هو الله ــل جلالهـ بالمباثر، أمّا في الثانية فهنالك وساطة بالحديث و هو النبي الأكرم (صلى الله عليه و آله وسلم).

2- حذف الكلمة: ورد في السورة فعلان متعدّيان بغير مفعول به، وهما (يتذكّر)، (قدّمتُ)، فقد حُذف المفعول به من كلا الفعلين

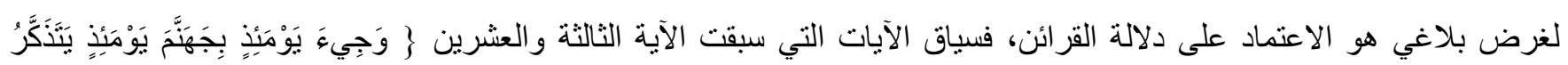
الْإنسََانُ وَأَنَّى لَلهُ الذَّكُرَى \}الفجر/23\{؛، كلها تدل على ما فرط الإنسان من ترك إكرام اليتيم، وعدم الحث على اطعام المسكين، وغير ها من أوصاف لا مقام لتعدادها، أو لاختز الها كلّها في مفعول واحد.

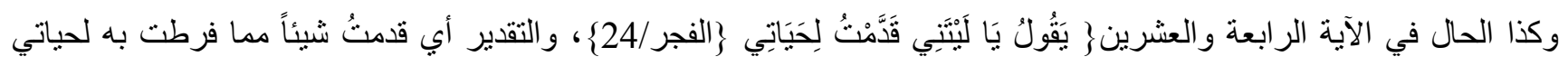
الحقّة، فلا خلل أو ركّة في الجملتين الفعليتين اللتين حُذف منهما المفعول به للاثثر الدلالي في سباق الآيات.

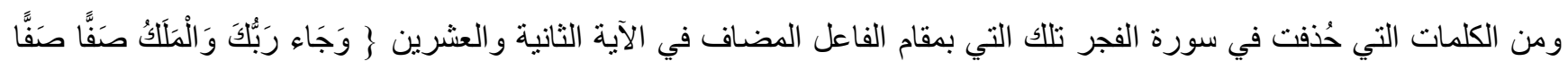

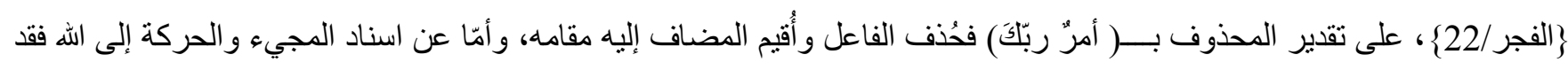
فال الزمخشري" وهو تمثيل لظهور آيات اقتداره وتبين آثار قهره وسلطانه مُتلت حاله في ذلك بحال الملك إذا حضر بنفسه ظهر بحضوره من آثار الهيبة والسياسة ما لا يظهر بحضور عساكره كلّها ووزر ائه وخو اصه عن بكرة أبيهم"[35] ب ـ المبني للمجهول : وردت في سورة الفجر ثلاثة أفعال مبنية للمجهول؛ واحدٌ منها مضارع، و الآخر ان ماضيان: 


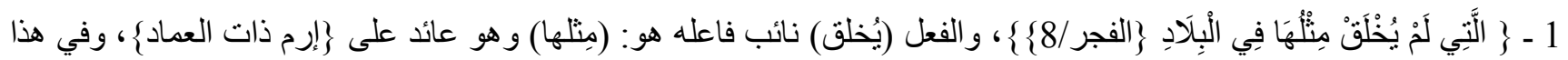
العود مسألتان: الأولى أن الضمير في (مِنلها) عائد على (إرم) وهي قبيلة لِعاد، إذ كانوا عظيمي الجنّة، وشديدي القوة، أمّا المسألة الأخرى: فالضمير عائد على (ذات العماد)، وقد حذف الفاعل للإيجاز ، أو لعلم بحسب مقام ذكر القصة، ولكن قد يكون حذف الفاعل الله و أعلم لقصد نفي الخلق سواء أكان للبلاد أم لقوم إرم في الحال والاستقبال؛ لأن الكلام سيق لأجل ذلك.

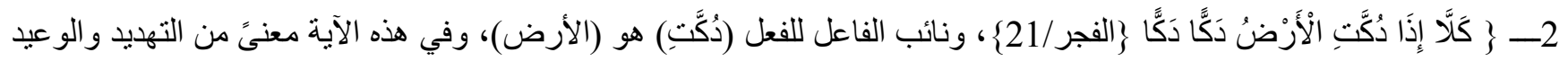
الثَديد، أي حقاً إذا دُكّت الأرض بأن جُعلت مثل الدكّة مستوية لا خلل فيها ولا تلول، فالدكّ هو حطّ المرتفع بالبسط[36]، وعن بناء الفعل للمجهول تقول عائشة بنت الثشاطئ:" يتّسق مع الظاهر والأسلوبية التي يطّرد فيها صرف النظر من الفاعل، في أحداث الساعة"[37]

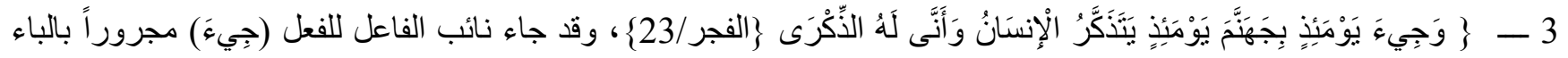
الز ائدة و هو (بجنهم)، و عن المعنى الإجمالي لهذه الآية التي ابتدأت بالفعل المبني للمجهول على وجه التشخيص و التجسيم والفاعلية[38]. 4- البنية الدلالية علم الدلالة أو دراسة المعنى، هو فرع من فروع اللغة وهو" قمة الدراسات اللغوية "39] كما يسميه الدكتور محمود السعران، و غيره من العلماء؛ إذ عدّ بعضهم أن فروع الدرس اللغوي هي خادمة لعلم الدلالة، ذلك أن الكثف عن النص وما يحمل من دلالة إجمالية أو دلالة كل كلمة فيها على حدة داخل هذه السياق الرصين، له أثز بالغ الأهمية. ولو مررنا بالمعاجم اللغوية التي تعرض لنا دلالة الكلمة ومعناها، فنجد يضع الكملة داخل سياق لغوي - جملة مفيدة- ويعطي المعنى الذي انتجه ذلك الترابط وتللك العلاقات بين الكلمات، ويستمر في سرد جمل أخرى منباينة الدلالة بالنسبة لتلك الكلمة؛ ليتضح من ذلك أن للكلمة جسد وروح أو معنى آخر باطن وظاهر ، أو كما يسميه المحدثون الدال والمدلول يجمع هذه الدلالات المتباينة الدلالة الكلمة الواحدة مرجع و احد، لا يكاد مغادرة معنى جامعا من ور اء اختلاف المر امي. وسنتناول في هذه البنية - بعون الله حقلين مهمين من علم الدلالة وهما (الدلالة المعجمية ودلالة السياق) في سورة الفجر، لنتعرف على ما جملته السورة المباركة من مفردات ودلالتها، مع وجودها داخل سياق الآيات الكريمة تقرّبا مما يكثفه النص القر آني. 


\section{أ-الالالة المعجمية:}

يعنى هذا الحقل بدر اسة مفردات اللغة من خلال تجميعها في حقول أو مجالات دلالية، إذ تتكون من مجمو عة من المعاني أو الكلمات المتقاربة التي تنماز بوجود عنصر أو ملامح دلالية مشتركة [40] .إذن الكلمات في المعجم ذات أبعاد دلالية عدة، تجعلها صالحة للاخول في أكثر من سياق ومن ثبوت ذللك لها يأتي بالضرورة تعدد معناها واحتماله في الإفراد [41]. فلو عرضنا جملا تتضمن الفعل (ضرب)، نحو(ضرب زيدُ بكراً)، و(ضربتْ الأرضنَ )، و(ضربَ فلانٌ عن الأمرِ)، فنرى أن المعنى في الجملة الأولى يعني (الايذاء)، وفي الجملة الثانية يعني (الحرث). وفي الثالثة :(أعرض عنه)...و هكذا ما لا نهاية من الأمثلة على ذلك.

وسنمر على بعض المفردات الأكثر حضوراً في السورة المباركة، موازنين بين دلالتيهما في المعجم وما أدت من معنى داخل سياق

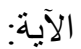

1_الفجر : وردت هذه الكلمة في الآية الأولى ((والفجر))، في معجم العين وتظهر دلالات عدة للكلمة، منها:

الفجر : ضوء الصباح. والفجر :الصبح و الفجر : المعروف، وما أكثر معروفه . و الفجر : تفجيرك الماء. والمفجر: الموضع الذي ينفجر منه الماء.[42]. وما جاء بالتفاسير عن هذه الكلمة لا يخرج عن دلالة اللفظة في المعجم، فيذكر الثيخ الطوسي (460) للهجرة: أن الفجر "شقَّ عمود الصبح فجره الله لعباده يفجره فجرا إذا أظهره في أفق المشرق مبشرا بإدبار الليل المظلم و إقبال النهار المضيء"[43]. ويزيد على هذا المعنى الشيخ الو احدي (486) للهجرة ويخصصه لهذه اللفظة أكثر، فيقول: "أقسم الله بفجره المحرّم فمنه تتفجر الألسنة، ويسنمر بعرض روايات في تلك الأية منها أنّه فجر العشرة الأولى من ذي الحجة، أو فجر يوم المنحر".[44]، ولا يكاد يخرج المفسرون جميعهم بحسب الرو اياتـ عن هذه التفاسير. [45] ليتضح أن دلالة الكلمة في المعجم - باختلاف وجودها في جمل متعددة ـ لا تخرج عمّا استعملت فيه، لا سيما أن الآية الأولى لم تتضمن كلمة غير (الفجر). لصاحب تفسير الأمثل إثارة لطيفة حري بنا أن نذكر ها، فبعد أن يستعرض جميع الآر اء في كلمة الفجر يقول " ولكن مفهوم الآية أوسع من أن تحدد بمصداق من مصاديقها، فهي تضم كلّما ذكر. وذهب بعضهم إلى أوسع مما ذكر حينما قالوا:هو كل نور يشٌّ وسط ظلام...و عليه، فبزوغ نور الإسلام ونور المصطفى (صلى الله عليه وسلم ) في ظلام 
الجاهلية هو من مصاديق الفجر، ويكون من مصاديقه كل ثورة قامت أو تقوم على الكفر والجهل والظلم على مرّ التأريخ، وحتى انقاح أوّل شر ارة يقظة في قلوب المذنبين المظلمة تدعو هم إلى التوبة فهو (فجر )"[46].

2_الثّفع و الوتر: الثثفع ضم الثيء الى مثله، ويقال للمشفوع :شفع، وقوله (و الثفع والوترج)، وقيل :الثشع المخلوقات من حيث إنها مركبات، كما قال (ومن كل شيء خلقنا زوجين\{. والوتر: هو الله من حيث إن له الوحدة من كل وجه [47]

قال أبو عبيدة :"الثّفع: الزكا، وهو الزوج، والوتر: الخنساء، وهو الفرد. وقال الأصمعي: كل فرد وتر، وأهل الحجاز يفتحون فيقولون: وتر في الفرد، ويكسرون في النّحل، ومن نحتهم من قيس، وتميم يسوونها في الكسر، ويقال في الوتر الذي هو الفرد: أوترتُ فلانا، أوتر

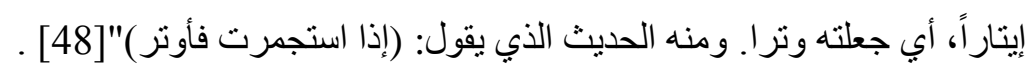

وفي تفسير هذه الآية يعبر الفخر الرازي عنها، فيقول "اضطرب المفسرون في تفسير الثفع والوتر، وأكثروا فيه، ونحن نرى ما هو أقرب (أحدهما) أنّا لثَفع يوم النحر والوتر يوم عرفة، و إنما أقسم الله بهما لثرفهما، أما يوم عرفة فهو يدور عليه أمر الحج كما في حديث حج عرفة،وأما يوم النحر هو يوم الحج الأكبر ، فلما اختص هذان اليومان بالفضائل لا جرم أقسم الله بهما"[49]. (صبّ)

قال ابن فارس (395) :"الصاد و الباء أصل وحاد، و هو إراقة الثيء، و إليه ترجع فروع الباب كله. من ذلك صبيت الماء أصبه صبّا. ويحمل على ذلك فيقال لما انحدر من الأرض صبب، وجمعه أصباب، كأنه شيء منصب في انحداره، وفي الحديث (أنّه كان صلى الله عليه و آله وسلم إذا مشى فكأنما يمشي في صبب"[50].

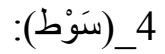
قال ابن فارس:"السن و الواو و الطاء أصل يدل على مخالطة الثيء الثيء. يقال سُطت الثيء:خلطت بعضه ببعض، وسوط فلان أمره

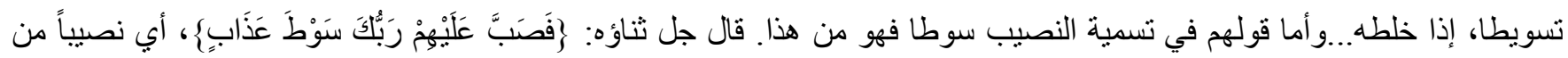
العذاب"[51]. وقال الراغب عن هذه الآية: "هذا تثبيها بما يكون في الدنيا من العذاب بالسوط، وقيل إثارة الى ما خلط لهم من أنواع العذاب"[52]، يتضح من هاتين اللفظتين (صب وسوط) الواردتين في الآية الثالثة عثرة : (فصب عليهم..) أنهما استعملتا استعارة لحال إنز ال العذاب و انحداره الذي جاء بهيئة السوط، والسوط يدل تارة على النصيب من العذاب، وتارة على المخالطة بين العذاب والمعذّب، كأما العذاب خالط جلودهم فلا يميز اللحم من الجلد. 
ويقول صاحب تفسير روح المعاني عن (فصب عليهم ربك):"أي أنزل سبحانه إنزالاً شديداً على كل طائفة من أولئك الطو ائف عقبب ما فعلت من الطغيان و الفساد. (سوط عذاب): أي سوطا من عذاب. على أنّ الإضافة بمعنى (من) و العذاب بمعنى المعذب به و المر اد بذلك ما حلّ بكل منهم من فنون العذاب التي شرحت في سائر السور الكريمة، والسوط في الأصل مصدر ساط يسوط إذا خلط"[53]. وقريب هذا المعنى أنّ المعنى أنّ المعذب يتو اتر عليهم العذاب تو اتر السوط على المضروب أو استعير لعذاب الدنيا.[54] .

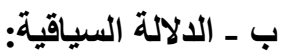

تؤكد هذه النظرية على أهمية الوقوق على السياقات المختلفة التي ترد فيه الكلمة من أجل الوقوف على معناها وقوفاً صحيحاء.[55]. ويتكون سياق الحال من مجموعة العناصر المكونة للحدث الكلامي. وتشمل هذه العناصر التكوين الثقافي للمشاركين في الحدث و الظروف الاجتماعية المحيطة به والأثر الذي يتركه على المشاركين به.]56]

ويرى صاحب هذه النظرية أن الوصول إلى معنى أي نص لغوي يستلزم تحليله على المستويات اللغوية المختلفة، ثم بيان هذا النص اللغوي ومقامه، ثم بيان الآثر الذي يتركه على من يسمعه.[57] . وقد تنبه علماء العرب القدماء إلى أهمية المقام (سياق الحال) في فهم دلالات الألفاظ، كما يشير إلى ذلك د.الراجحي، بأن ما يشير إلى فكرة السياق الحال من هذه الإشار ات ما أفرده المفسرون في معرفة أسباب النزول.588] 1 دلالة التعريف والتكير: وردت كلمة (الليل) في السورة مرتين، جاءت في الآية الثانية منكرة مجموعة بصيغة منتهى الجموع ( وليال عشر). وجاءت في الآية الرابعة معرفة بال التعريف، أوبأل الجنس (و الليل إذا يسر)، وفي كلا الآيتين قسم، جاء التنكير في الأولى لليال معينة أقسم بها الله تعالى؛ لعظمتها وفضلها ومكانتها عنده سواء أكانت مخلوقة حال الأولى أم لم تخلق بعد، وما تشعب من الآراء في بيان الآيات عند المفسرين إلا دلالة على أن التنكير للتعظيم هنا. ولرصف الأحداث والمو اقف على مدى الأيام ومن ثم رصدها لا على سبيل الحصر و إنما معرفة عظمة المقسم به، كما أن سياق القسم كلها جاءت معرفة، وهذا لا يعني أنها مكثوفة محددة واضحة، وتفسير ها يأتي بمقتىى

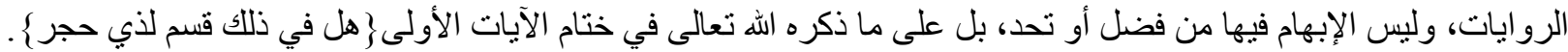
أما المعرفة في \}و الليل إذا يسر فهنا من سياق الحال أنه ورد الكلام عن مسير الليل بوقته،لا عن الليل، فما أدق هذا التعبير وأجمله؟ فقد نسب السير إلى الليل وكأن الوصف يقول: "بأن الليل موجود حسي له حسّ وحركة وهو يخطو في ظلمته وصو لا لنور النهار، نعم قسما 
بالظلام المتحرك السائر نحو النور،لا الثابت الذي يثير الخوف والرعب في الإنسان " [59] ـ و الذي عليه أكثر المفسرين أنّه ليس المراد منه ليلة مخصوصة بل العموم[60].

\section{2- العدول عن دلالة لفظة دون أخرى:}

من أسباب العدول عن لفظة دون أخرى هو التفريق بين لفظة تحمل معنى أوسع وأشمل من قرينتها، أو أنّ للفظة ما استعمالا أصلح من غير ها في سياق جملة معينة، و هذا غالبا ما يتجلى في الترادف، وقد جاءت أفعال في وصف أحول صنف من الناس، يخاطبهم الله بـ ( :(تُكْرِمُون) في الآية السابعة عشرة: ((كلا بل لا تكرمون اليتيم))، والكرم: "إذ وصف الله تعالى به فهو اسم لإحسانه وانعامه المتظاهر، نحو قوله: (إنّ ربي غني كريم\{ النمل:40، وإذا وصف به الإنسان فهو اسم للأخلاق والأفعال المحدودة التي تظهر منه، ولا يقال:هو كريم حتى يظهر منه"[61]. لذلك كان التعبير أدق من غيره على أنّه ليس المر اد من إكر ام اليتيم هي المساعدة المالية، أو الاكتفاء بعدم التقرب إلى أمواله بسوء، فلو كان التعبير بكلمة (بل لا تعبنون، أو بل لا تساعدون، أو بل لا ترفقون) لكان المعنى ضيقا غير شامل. ورد الفعل (تُخاضُون) في الآية الثامنة عشرة: (و لا تحاضون على طعام المسكين\{، يقال حضضته وحثثته و(تحاضون ) مثل فاعلته، وفعلته، إلا أن المفاعلة بين اثثين أو أكثر، بمعنى لا تحافظون [62]. ولو استعمل الفعل تحافظون لما أدى من دلالة معنوية، وآخرى نفسية تستشف من سياق الآيات الو افعة بعد الردع بـ: (كلا). وكذا الحال في مجيء الفعلين (وتَاكُلون، وتَحبُُون)، في الآية التاسعة عشرة: ((وتأكلون التراث ...)) وفي الأية العشرين: ((وتحبون المال ..))، وكلا زاد من اتساع المعنى أنّ الجملتين تضمنتا مفعولين مطلقين: (تأكلون أكلا، وتحبون حبا ) وكلا من المفعولين قد وصفا بـ (لمّا، وجمّا). كما أن هنالك استعارة في جملة (تأكلون)، وكثر ما تكون جملة الاستعارة أبلغ من جملة صريحة . 
1_ لكل نص بنيته الخاصة به، التي تعد هويته التي ينماز بها عن بقية النصوص، التي تفتح قناة التواصل بين النص والمتلقي للوقوف على قصدية النص.

2- ساهمت البنية الصوتية في إظهار دلالات النص جلياً ماثلاً أمام القارئ من خلال الفاصلة والنبر والتنغيم الذي له دور فونيمي وآخر

$$
\text { نفسي. }
$$

3- كما قامت الصيغ و الأوزان بدورٍ يتناسق و المعنى الذي قُدّدر لتلك الكلمة، لتكون البنية الصرفية، وما فيها من تضعيف ومعنىً بكل ما يرمبه القصد للكلمة المفردة .

4 ـ لعبت البنية التركيبة دوراً في التأليف بين الصورة الذهنية المنشكلة في تلك الجملة العربية، وما كان فيها من ذكر وحذف وبناء للمجهول.

5- وقد تظافرت كل من البنيتين التركيبية و الدلالية لتستجلي جمالية تماسك النص وترتقي بالقصدية إلى مر اتبها العليا. 
[1] ينظر : برهان الدين أبي الحسن ابر اهيم البقاعي ـ مصاعد النظر للإشر اف على مافى مقاصد السور ـ (855ه)، تقديم وتحقيق وتعليق

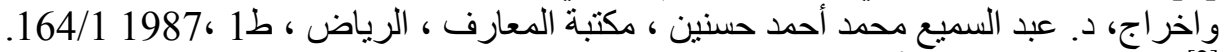

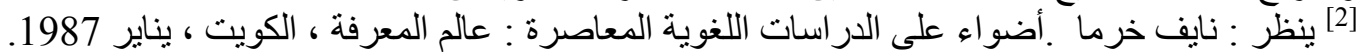

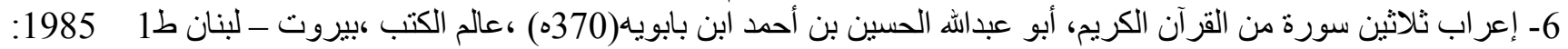

[3] ينظر : الثيخ محمد طاهر ابن عاشور ـ تفسير التحرير والتنوير، الدار التونسية للنشر ، ط1 ، 1982. .76 .75 [3] محمد قطب عيد العال .الاداء التصويري و إيقاع الفواصل في القرآن الكريم : مجلة الداعي الثهرية الصادرة عن دار العلوم ديوبند ،

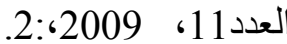

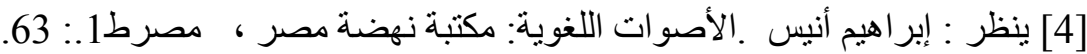

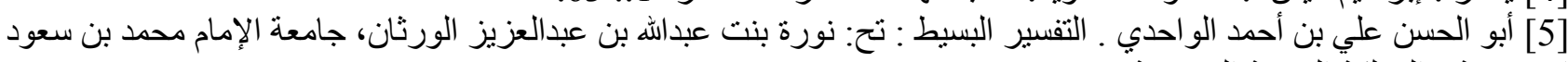

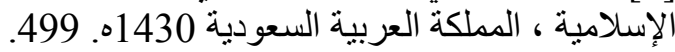

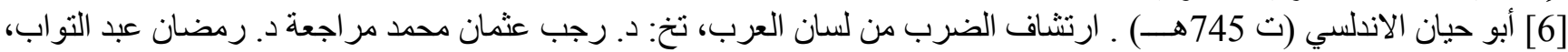

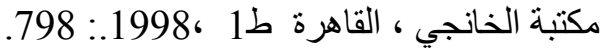

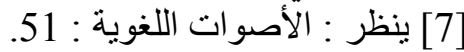

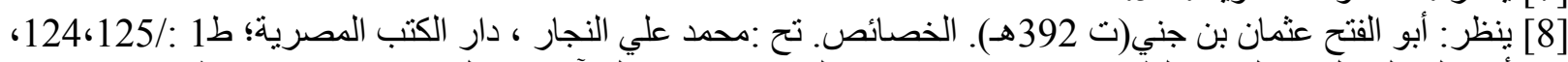

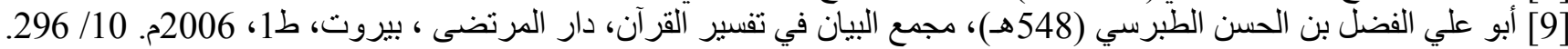

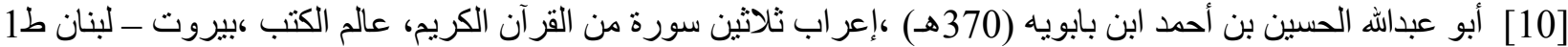
$80 ؟ 1985$ 98:

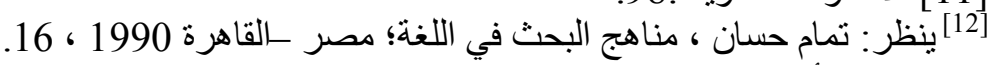

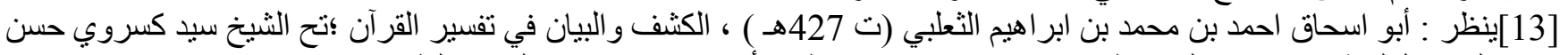

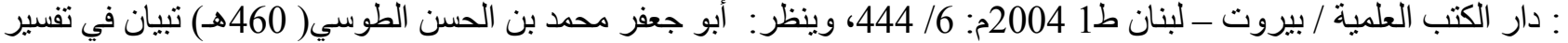

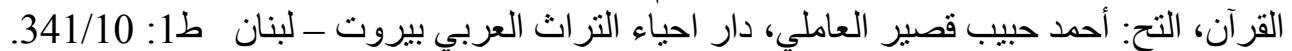

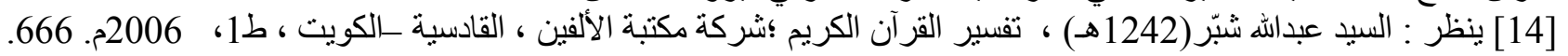

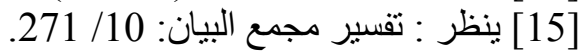
[16] محمود السعر ان، علم اللغة مقدمة للقارئ العربي ؛ دار النئ النهضة العربية للطباعة و النشر : بيروت_لبنان،ط1 ، 192.

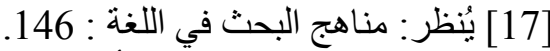

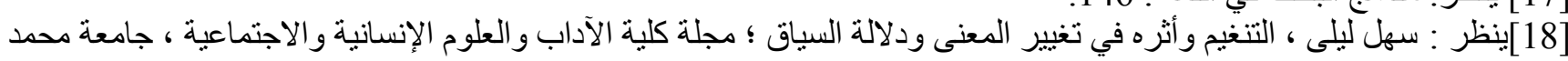

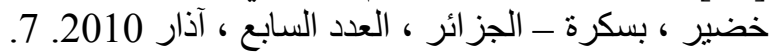

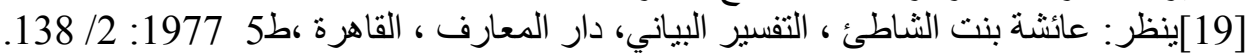
[20] ينظر: [20] :

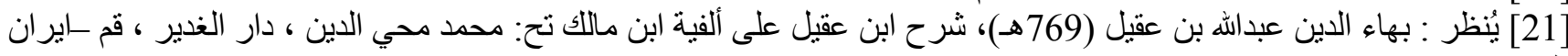

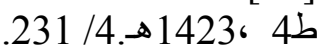
271/10 : 231/23] مجمع البيان.

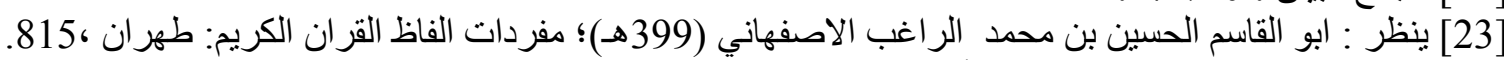

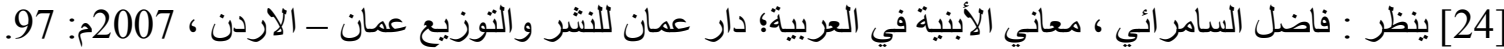

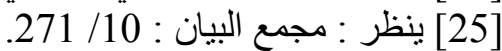
137 [26] التفسير البياني : 126$]$

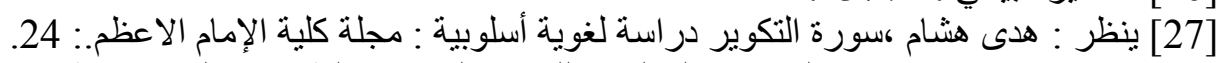

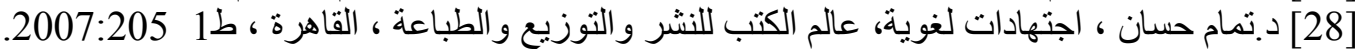

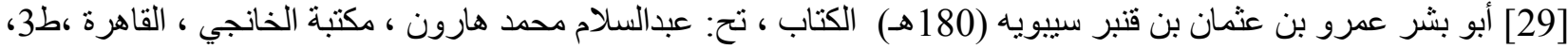
184،185/1988.4

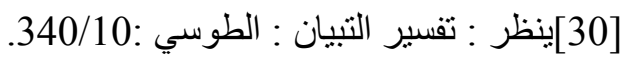

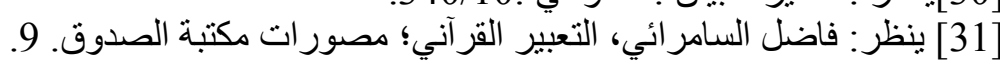


[32]ينظر : جلال الدين محمد بن أحمد المحلي (864هـ)، تفسير الجلالين ، العلامة جلال الدين عبدالرحمن السيوطي (911هـ) ، تح: د.

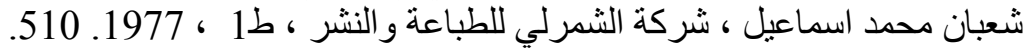
[33] محمد الر ازي فخر الدين ابن العلامة ضياء الدين عمر ( 604هـ) ،التفسير الكبير ومفاتيح الغيب، دار الفكر للطباعة والنشر، لبنان

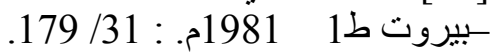
17/10 [35] تفسير التبيان:

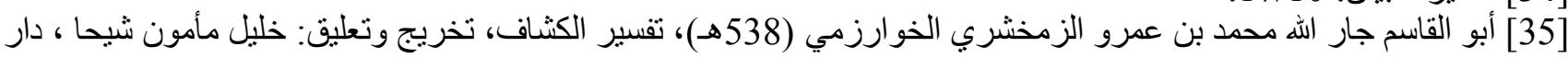
المعرفة بيروت - لبنان ط3 1351 2009م: 1202.

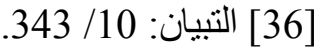

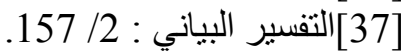
338]

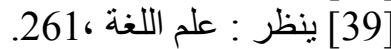

[40] ينظر: عبدالكريم محمد حسن جبل ، في علم الدلالة در اسة تطبيقية في شرح الانباري للمفضليات؛ دار المعرفة الجامعية ،مصر

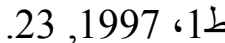

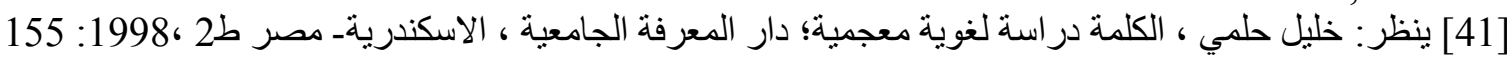

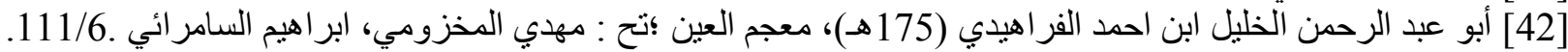

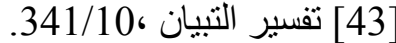

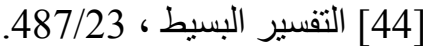
[45] [46سير الرازي ، 162/31.

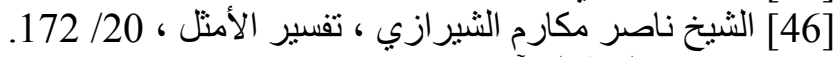

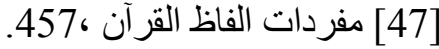

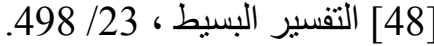

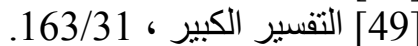

[50] أبو الحسين أحمد بن فارس بن زكريز الفيا (395هـ)، معجم مقاييس اللغة ؛تح، عبد السلام محمد هارون ،دار الفكر ، بيروت ـلبنان

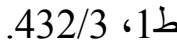

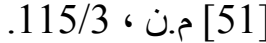

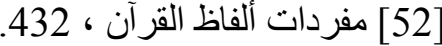

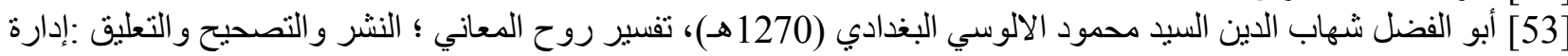

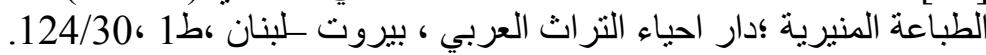

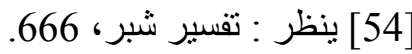

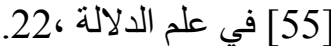

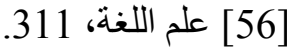

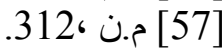

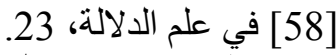

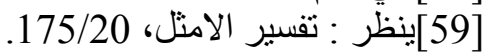
[60] ينظر : التفسير الكبير، 165/31. [616] مفردات الفاظ القرآن الكريم، 707 ـ

346/10 ينظر : تفسير التبيان، 